\title{
Genetic Relatedness among Cultivars of the Greek Plum Germplasm
}

\author{
Ioannis ATHANASIADIS ${ }^{1}$, Nikolaos NIKOLOUDAKIS², Marianna HAGIDIMITRIOU ${ }^{1 *}$ \\ ${ }^{1}$ Agricultural University of Athens, Department of Crop Science, Pomology Laboratory, Iera Odos \\ 75, 11855 Athens, Greece; marianna@aua.gr (*corresponding author) \\ ${ }^{2}$ Hellenic Ministry of Rural Development and Food, Vegetative Propagation Material Control Station, Greece; an2u021@minagric.gr
}

\begin{abstract}
Genetic diversity of the Greek plum germplasm collection was investigated using a combined RAPD and ISSR molecular markers approach. Twenty-six genotypes held at NAGREF-Naoussa were analyzed, producing in total 150 loci, of which 116 were polymorphic. Both techniques were highly informative and had a discrimination power greater than 0.9 . RAPD and ISSR dendrograms were fairly correlated. The accessions were clustered according to ploidy and species. All Prunus domestica genotypes were grouped together and showed greater similarity to $P$. insititia and $P$. cerasifera genotypes compared to $P$. salicina, which was found genetically diverged. Bayesian structural analysis revealed significant admixture among genotypes. Greek varieties $P$. domestica 'Goulina' and 'Asvestochoriou' exhibited a distinctive genetic background, differentiating them from foreign varieties. This feature could make them attractive for breeding programs, since they can increase genetic diversity.
\end{abstract}

Keywords: AMOVA, ISSR, Prunus spp., RAPD, STRUCTURE

\section{Introduction}

Plum species belong to genus Prunus L. (Rosaceae), and are naturally distributed in the temperate regions of the Northern Hemisphere (Mabberley, 2008). This taxa is a diverse group of plants with various botanical species that have been cultivated for 2000-4000 years (Banegal, 1954). The most economically important plum species are generally classified into two groups: the European (Prunus domestica L.) and the Japanese (Prunus salicina Lindl.) plum.

It has been proposed that $P$. domestica originated in Southern Europe or Western Asia around the Caucasus Mountains and the Caspian Sea (Cullinan, 1937). However, it is also widespread in the Balkans and the Mediterranean countries, including Greece. Prunus domestica has been cultivated in Europe for at least 2000 years, but and up to now no distinctly wild form is documented (Westwood, 1993). Thus the evolution of the European plum remains a controversial matter. Crane and Lawrence (1952) suggested that $P$. domestica, a hexaploid $(2 \mathrm{n}=6 \mathrm{x}$ $=48)$, originated through an interspecific cross between the diploid $(2 \mathrm{n}=2 \mathrm{x}=16)$ P. cerasifera Ehrh. (Myrobalan plum) and the tetraploid $(2 \mathrm{n}=4 \mathrm{x}=32) P$. spinosa L., either through chromosome doubling of the hybrid triploid or through the action of unreduced parental gametes. On the contrary, Zohary (1992) proposed that $P$. domestica was an autopolyploid derived from $P$. cerasifera - rather than an allopolyploid, while Eryomine (1991) suggested that a number of species, such as $P$. microcarpa C.A. Mey., $P$. salicina, $P$. armeniaca L., and $P$. persica L., could have participated in the lineage of $P$. domestica.
Prunus salicina, a diploid $(2 \mathrm{n}=2 \mathrm{x}=16)$ species domesticated in China from ancient times (its wild forms are believed to thrive in the regions of Shensi and Kansu), was introduced in Japan 200-400 years ago (Ramming and Cociu, 1990). These plums were initially improved in Japan and later, to a much greater extent, in the United States (Okie and Ramming, 1999) where subsequent breeding resulted in larger fruit cultivars (latter half of the 19th century).

Traditionally, classification within the genus Prunus was mostly based on fruit morphology and thus being debatable (Aradhya et al., 2004). Furthermore, phenotype is influenced by environmental factors, mainly as a result of the long generation time and large size of the trees. Therefore, precise characterization for Prunus spp. and germplasm evaluation is a prerequisite, in order to develop effective conservation and breeding strategies. In order to indisputably explore the genetic diversity of these numerous plum varieties and their interrelationships, molecular marker technologies can prove valuable.

In the present study, two different molecular marker approaches (RAPD and ISSR) were employed in order to evaluate the degree of genetic diversity of the Greek National Plum Collection held at NAGREF-Naoussa, and to further analyze the genetic structure of three related plum species: P. domestica, P. salicina and $P$. insititia (L.) C.K. Schneid. Additionally, the elucidation capability and effectiveness of RAPD and ISSR markers on genetic relationships among plum genotypes was examined. 
492

\section{Materials and methods}

\section{Plant material and DNA extraction}

Twenty-two prune varieties ( $P$. domestica and $P$. salinica), three $P$. insititia and one $P$. cerasifera accessions held at NAGREF-Naoussa, were included in the present study (Tab. 1).

Tab. 1. Plant material utilized for RAPD and ISSR analyses, including the number assigned, cultivar or common name, species and assignment of each variety to clusters based on Bayesian simulations $(K=2, K=5)$

\begin{tabular}{|c|c|c|c|c|}
\hline \multirow[t]{2}{*}{$\mathrm{N}^{\circ}$} & \multirow{2}{*}{$\begin{array}{l}\text { Cultivar or } \\
\text { common name }\end{array}$} & \multirow[t]{2}{*}{ Species } & \multicolumn{2}{|c|}{$\begin{array}{l}\text { Assignment } \\
\text { to clusters }\end{array}$} \\
\hline & & & $K=2$ & $\mathrm{~K}=5$ \\
\hline 1 & 'Goulina' & Prunus domestica & 1 & 1 \\
\hline 2 & 'Asvestochoriou' & Prunus domestica & 1 & 1 \\
\hline 3 & 'Bluefree' & Prunus domestica & 1 & 1 \\
\hline 4 & 'Black Beauty' & Prunus salicina & 2 & Admixed \\
\hline 5 & 'Friar' & Prunus salicina & 2 & 2 \\
\hline 6 & 'Calita' & Prunus salicina & Admixed & Admixed \\
\hline 7 & 'Stanley' & Prunus domestica & 1 & 1 \\
\hline 8 & 'Angeleno' & Prunus salinica & 2 & Admixed \\
\hline 9 & $\begin{array}{l}\text { 'Anna Späth' } \\
\text { Oradea }\end{array}$ & Prunus domestica & 1 & Admixed \\
\hline 10 & 'Anna Späth’ Pitesti & Prunus domestica & 1 & 1 \\
\hline 11 & 'President' & Prunus domestica & 1 & 1 \\
\hline 12 & 'Tuleu gras' bistro & Prunus domestica & 1 & 1 \\
\hline 13 & 'Kisnanai' & Prunus domestica & 1 & Admixed \\
\hline 14 & 'Tuleu dulce' & Prunus domestica & 1 & Admixed \\
\hline 15 & $\begin{array}{l}\text { 'Koromilo } \\
\text { roumanias' }\end{array}$ & Prunus insititia & 1 & 3 \\
\hline 16 & 'Feher besztercei' & Prunus domestica & 1 & 1 \\
\hline 17 & 'Kesley' & Prunus salicina & Admixed & Admixed \\
\hline 18 & ' $11 / 11 '$ & Prunus insititia & 1 & 3 \\
\hline 19 & 'Scoldus' SS & Prunus domestica & 1 & 1 \\
\hline 20 & $\begin{array}{l}\text { 'Mirabelle de } \\
\text { Nancy' }\end{array}$ & Prunus domestica & 1 & Admixed \\
\hline 21 & ‘Gilej’ & Prunus domestica & 1 & Admixed \\
\hline 22 & 'Daw dean' & Prunus insititia & 1 & Admixed \\
\hline 23 & 'Myrobalanos' & Prunus cerasifera & Admixed & Admixed \\
\hline 24 & 'Santa Rosa' & Prunus salicina & 2 & Admixed \\
\hline 25 & 'Black Diamond' & Prunus salicina & 2 & Admixed \\
\hline 26 & 'Black Gold' & Prunus salicina & Admixed & Admixed \\
\hline
\end{tabular}

Young leaves were collected, cleaned with moist paper towels and flash-frozen in liquid nitrogen. The tissue was stored at $-80^{\circ} \mathrm{C}$. Genomic DNA was extracted as previously described by Doyle and Doyle (1987). DNA concentration and quality was calculated spectrophotometrically (Unicam Helios; OD260nm/OD280nm ratios were above 1.8 ) and confirmed with $1 \%$ agarose electrophoresis using standard $\lambda$-phage molecular weights. All samples were diluted at a concentration of $5 \mathrm{ng} / \mu \mathrm{L}$ by adding T.E., for use in PCR reactions, and stored at $-20 \mathrm{oC}$.

\section{$R A P D$ and ISSR reactions}

More than 30 RAPD primers (Invitrogen) were initially tested in preliminary experiments of which ten resulted in unambiguous polymorphic products among genotypes. For the ISSR analysis ten primers were tested and five were selected (Tab. 2).

Tab. 2. List of the primers used in RAPD and ISSR analyses

\begin{tabular}{|cccc|}
\hline Primer & Sequence (5-3) & Primer & $\begin{array}{c}\text { Sequence } \\
(5-3)\end{array}$ \\
& RAPD & \multicolumn{2}{c|}{ ISSR } \\
\hline OPB-1 & GTAGACCCGT & 818 & $(\mathrm{CA})_{8} \mathrm{G}$ \\
\hline OPB-11 & GTTTCGCTCC & 825 & $(\mathrm{AC})_{8} \mathrm{~T}$ \\
\hline OPH-13 & GACGCCACAC & 844 & $(\mathrm{CT})_{8} \mathrm{RC}$ \\
\hline OPH-18 & GAATCGGCCA & 861 & $(\mathrm{ACC})_{6}$ \\
\hline OPAH-17 & CAGTGGGGAG & 889 & DBD $(\mathrm{AC})_{7}$ \\
\hline OPBD-7 & GAGCTGGTCC & & \\
\hline OPA-9 & GGGTAACGCC & & \\
\hline RAPD-3 & AGAACCGAGG & & \\
\hline RAPD-5 & TCCAACGGCT & & \\
\hline RAPD-20 & TCCGGGTTTG & & \\
\hline
\end{tabular}

The RAPD and ISSR protocols followed Despotaki et al. (2011). The amplified products were resolved on 1.5\% and $2 \%$ agarose gels respectively, buffered with $1 \mathrm{x}$ TAE and stained with $\mathrm{EtBr}$.

\section{Data analysis}

The RAPD/ ISSR banding patterns were visualized and photographed using a Canon A630 and a UV table (Serva). Reproducible fragments were scored as present (1)/absent (0) for each reaction and were assembled in a binary data matrix table. Comparison of the discriminating capacity, level of polymorphism and informativeness were estimated following the procedure described by Belaj et al. (2003). Genetic similarities between taxa were calculated using the Dices coefficient and an UPGMA dendrogram was constructed. Mantel test was used to compute the cophenetic correlation, i.e., to test the goodness of fit of the cluster analysis to the similarity matrix and the goodness of fit of cluster analysis to the similarity matrices (999 permutations). All of the above analyses were performed using the NTSYS-PC 2.01 software (Rohlf, 2000). Bootstrap analysis was performed using the FreeTree program (Pavlicek et al., 1999) and displayed with TreeView (http:// taxonomy.zoology.gla.ac.uk/rod/treeview.html).

Genotypic variations were assessed across various populations by means of analysis of molecular variance (AMOVA) using GenALEx 6 (Peakall and Smouse, 2006). 
The significance of the resulting variance components and inter-population genetic distances were tested using 999 random permutations. Bayesian model-based clustering approach to identify the genetic structure in the plum germplasm was performed using STRUCTURE 2.3.4 (Pritchard et al., 2000) based on the combined RAPD and ISSR data. The STRUCTURE algorithm was run using both the admixture model and the no admixture model, with 10 independent replicate runs per $\mathrm{K}$ value (number of clusters) ranging from 1 to 10 . Each run involved a burning period of 20000 iterations, and a post burning simulation length of 20000. Validation of the most likely number of clusters $\mathrm{K}$ was performed using the Structure Harvester online application (http://taylor0.biology.ucla. edu/structureHarvester).

\section{Results and discussion}

Within Prunus, genetic relationships between $P$. domestica, $P$. insititia and $P$. cerasifera, are far from clarified. Still, delineation of the diverse taxa involved and information on their morphological and genetic diversity is an indispensable and crucial tool for their proper utilization. Extensive polyploidisation (Zohary, 1992; Woldring, 2000), hybridization, introgression (Stace, 1975; Woldring, 2000) and a long cultivation history (Zohary and Hopf, 1994; Woldring, 2000; Nielsen and Olrik, 2001) led the European Prunus taxa into a complex biological species concept with overlapping species relationships (Depypere et al., 2009). Furthermore, it resulted in a broad genetic variation and transitional states between and within the different taxa.

In the present study, we adopted an integrated method using the resolving power of molecular markers (RAPD and ISSRs) to validate genetic relationships among plum species and cultivars, and to determine the genetic diversity of the Greek plum germplasm. The final aim is to discover the genetic composition and the possible overlapping of the plum genepool which still remains vastly uncharted. Out of 30 RAPD and 10 ISSRs primers tested, 10 RAPD and 5 ISSRs primers were retained for their ability to produce unambiguous and polymorphic bands (Tab. 2). In total 106 RAPD markers were amplified of which 80 were polymorphic (Tab. 3).

Each primer amplified six to 16 loci (three to 12 polymorphic) resulting to an average of 10.6 bands ( 8 polymorphic) per primer. The most prolific RAPD primer was OPAH-17, amplifying 16 DNA bands, while the least productive was OPA-9, detecting only six loci. The most polymorphic RAPD markers were amplified by RAPD20 and RAPD-5 (90\%) and the least were produced by OPBD-7 and OPA-9 primers (50\%). Respectively, for the ISSR analysis, in total 44 loci were detected (36 polymorphic). Each primer produced eight to 11 DNA bands (six to eight polymorphic), and on average 8.8 loci were amplified ( 7.2 were polymorphic). The most prolific ISSR primer was 889 that amplified 11 loci and the least were 818,825 and 861, producing eight loci. Strikingly, all loci amplified by primers 818 and 825 were polymorphic. On the contrary, primer 889 revealed the lowest polymorphic proportion (54\%).

Tab. 3. Levels of polymorphism and comparison of the discriminating capacity of RAPD and ISSR markers in 26 Prunus spp. genotypes

\begin{tabular}{|cccc}
\hline Index with their abbreviations & & RAPD & ISSR \\
\hline Number of assay units & $U$ & 10 & 5 \\
\hline Number of non-polymorphic bands & $n_{n p}$ & 26 & 8 \\
\hline Number of polymorphic bands & $n_{p}$ & 80 & 36 \\
\hline Average number of polymorphic & $n_{p} / U$ & 8 & 7.2 \\
bands/assay unit & $L$ & 106 & 44 \\
\hline Number of loci & $n_{u}$ & 10.6 & 8.8 \\
\hline Number of loci/assay unit & $T_{p}$ & 147 & 76 \\
\hline Number of Banding pattern & $I$ & 14.7 & 15.2 \\
\hline Number of patterns/assay unit & $C$ & 0.07 & 0.09 \\
\hline Average Confusion Probability & $D$ & 0.93 & 0.91 \\
\hline Average discriminating power & $D_{L}$ & 0.90 & 0.88 \\
\hline Average limit of discriminating power & $P$ & 9.81 & 8.33 \\
Effective number of patterns/assay unit & & & \\
\hline
\end{tabular}

Generally, ISSR data revealed lower similarity values than RAPD. The Mantel matrix correspondence test was used to compare the goodness of the fit of each similarity matrix. Both techniques had well-fitted cluster analysis to their corresponding similarity matrix; 0.89 for RAPD and 0.80 for ISSR. Likewise, the correlation coefficients were statistically significant for both marker systems. RAPD and ISSR similarity matrices were moderately correlated (0.60). However, correlation between their corresponding dendrograms was significantly higher (0.79).

Both marker techniques proved to be highly effective in discriminating the 26 genotypes analysed, since the majority of bands were polymorphic amongst genotypes (more than $75 \%$ ). On average, RAPD produced more polymorphic bands per assay (80 over 36 for ISSR; Tab. 3). However, ISSR were proven to be more prolific in terms of banding patterns per assay; 15.2 (ISSR) versus 14.70 (RAPD), on average. RAPD were also more informative since they produced 9.81 effective patterns per assay against 8.33 produced by ISSRs. Nonetheless, both techniques were highly informative, since they both had an average discrimination power higher than 0.91 . The number and percent of polymorphic loci, diversity index, effective multiplex ratio, and marker index were higher for RAPD than for ISSR markers, similar to previous reports by Kumar et al. (2009) and Aran et al. (2012) for plum germplasm. In total, 150 loci were detected, which is comparable to results reported by Shimada et al. (1999), Casas et al. (1999) and Hend et al. (2009) using 20, 13 and 10 RAPD primers, respectively. The high discriminating 
494

power of the primers used shows their efficiency and confirms the genetic diversity of the accessions studied, a result supported by the distance matrix among genotypes $(0.50$ 0.97). Hend et al. (2009) obtained a $97.3 \%$ polymorphism and a range of genetic similarity between 0.18-0.80 among genotypes. However, Shimada et al. (1999) also studying genetic variation of plum cultivars using RAPD markers, reported a $24 \%$ polymorphism and a similarity index that ranged from 0.62 to 1 . It is noteworthy that the Hend et al. (2009) study focused on indigenous plant material, while samples for the present study and that of Shimada focused on commercial genotypes. The higher diversity among indigenous genotypes compared to that of commercial ones, can be addressed by the genetic drift due to selection within commercial cultivars (Aran et al., 2012).

Both markers showed a high degree of similarity in topologies (data not shown), though with some minor differences in the positioning of some genotypes at the main groups. Clustering reflected relationships among most of the accessions, upon their species genotype/ploidy. Cluster analysis was carried out by combining the two sets of marker profiling data and a consensus phenogram was constructed (Fig. 1).

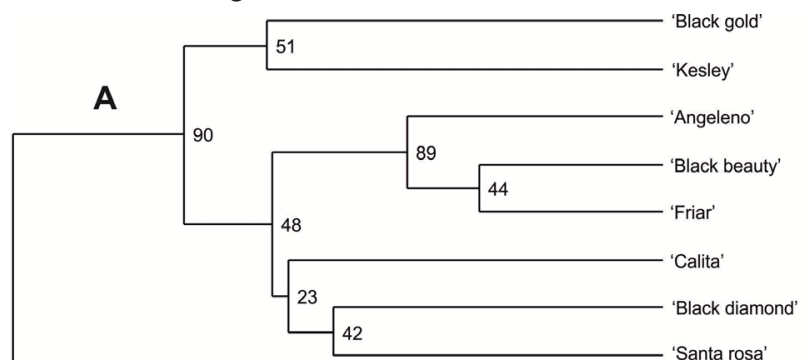

100

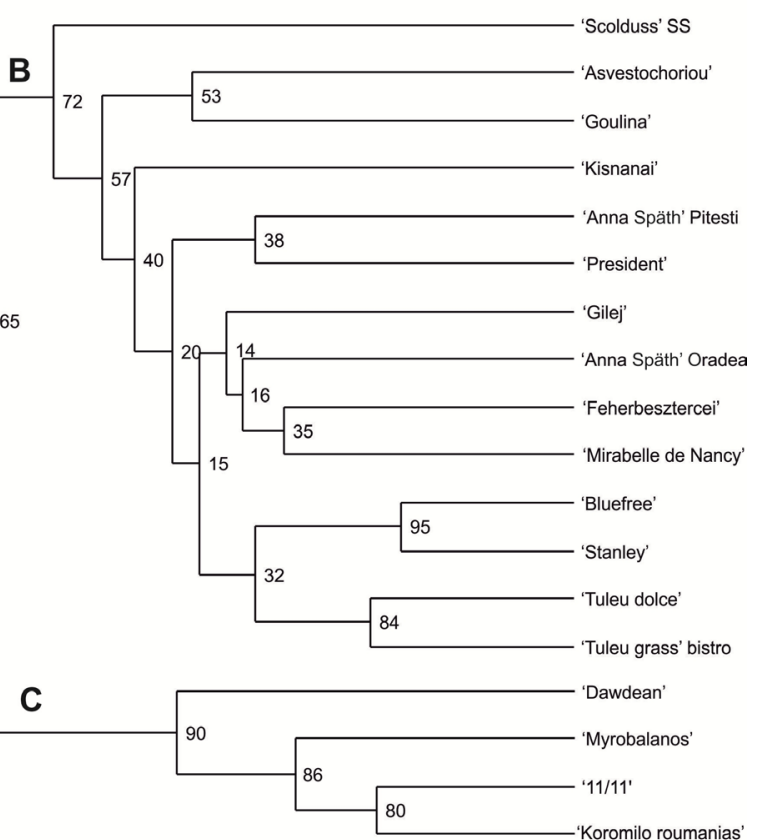

Fig. 1. RAPD and ISSR consensus dendrogram and bootstrap analysis. Bootstrap support values, based on 100 replications are presented on nodes

Combined RAPD and ISSR analysis broadly grouped the 26 accessions into three distinct clusters showing relation on the basis of species genotype. The bootstrap values were relatively high within and between species. Species were grouped into three clusters.

Cluster I had a bootstrap value of $90 \%$. Within this cluster all $P$. salicina accessions (eight in total) were grouped together with cultivars 'Black Gold' and 'Kesley', which formed an outgroup. The sub-clustering of the Japanese plums had a strong bootstrap support since high affinity was observed (bootstrap values from $23 \%$ up to $89 \%$ ) as supported from genetic distances among plums. High relatedness was depicted within the 'Angeleno', 'Black Beauty' and 'Friar' cultivars that formed a subgroup and within cultivars 'Calita,' 'Black Diamond' and 'Santa Rosa' that grouped together and parted from the former subgroup by a $48 \%$ bootstrap value.

Group II contained all hexaploid $P$. domestica accessions with cultivar 'Scoldus' SS as an outgroup. Furthermore, within this cluster the Greek cultivars 'Asvestochoriou' and 'Goulina' were grouped together with 57\% bootstrap separation from the hexaploid plum core. The other cultivars 'Anna Späth' (Oradea) and 'Anna Späth' (Pitesti) had little affinity among them and were clustered together with foreign cultivars. In particular, cultivar 'Anna Späth' (Pitesti) had moderate homology to 'President' cultivar (38\% bootstrap support) and 'Anna Späth' (Oradea) was clustered together with cultivars 'Gilej', 'Feher besztercei' and 'Mirabelle de Nancy'. The highest homology between this group was detected among cultivars 'Bluefree' and 'Stanley' (95\% bootstrap support) and 'Tuleu dulce' and 'Tuleu gras' bistro ( $84 \%$ bootstrap support). Finally, Cluster III comprised all $P$. insititia accessions and the P. cerasifera genotype. All genotypes were highly affiliated having bootstrap support more than $80 \%$.

Analysis of molecular variance for the plum entries revealed that the highest proportion $(64.05 \%)$ of the total genetic diversity was present within the three types. The highest variability was recorded for the $P$. domestica group $(S S=210.786)$, followed by P. salicina $(S S=116.000)$ and $P$. insititia (SS $=24.667)$. AMOVA also revealed that the genetic distance between clusters was significant (Fst $=$ $0.359, \mathrm{p}=0.001)$. Fst values suggest the presence of divergence between Prunus types. Prunus domestica group is clearly distinguished from $P$. salicina (Fst $=0.358, \mathrm{p}=$ 0.001 ) and $P$. insititia (Fst $=0.321, \mathrm{p}=0.001$ ). The lowest genetic affinity was found among the $P$. salicina and $P$. insititia species (Fst $=0.411, \mathrm{p}=0.007$ ) as it was also observed based on the genetic distances and the corresponding dendrogram.

The Bayesian analysis of genetic structure revealed interesting results. Based on the Evannos delta-K method, maximum $\Delta \mathrm{K}$ values were obtained for $\mathrm{K}=2$ and $\mathrm{K}=$ 5 for the admixture model; while for the no-admixture 
model maximum $\Delta \mathrm{K}$ values were obtained only for $\mathrm{K}=$ 5 (data not shown). For this value ( $\mathrm{K}=2$, no admixture model), $P$. domestica and $P$. insititia grouped together and P. salicina made up the second cluster (Fig. 2a).
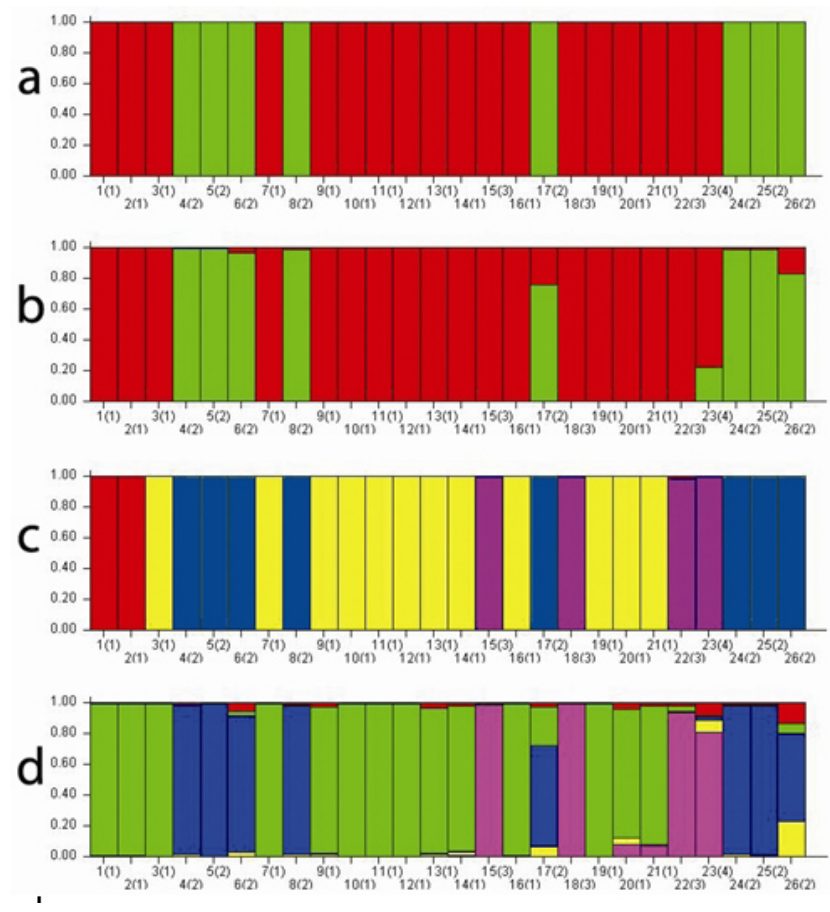

Fig. 2. Bar plot of the results from the Bayesian analysis on plum species genotypes indicated in Tab. 1. On the horizontal axis (1): Prunus domestica; (2): Prunus salicina; (3): Prunus insititia (4): Prunus cerasifera. a: $\mathrm{K}=2$, no admixture model. b: $\mathrm{K}=2$, admixture model. c: $\mathrm{K}=5$, no admixture model. $\mathrm{d}$ : $\mathrm{K}=5$, admixture model

However, in the admixture model, some Prunus spp. individuals were admixed between the two populations (Fig. 2b; Tab. 1). Considering a greater number of populations, $P$. insititia appeared as a new population (Fig. $2 \mathrm{~d}$ ) and $P$. salicina revealed more complex genetic structure showing the highest proportion of admixed individuals. Strikingly, for the no admixture model and for $K=5$, the Greek cultivars 'Goulina' and 'Asvestochoriou' revealed a unique genetic profile, separating them from the other $P$. domestica accessions (Fig. 2c).

In both the UPGMA clustering and the Bayesian approach, classification was according to species genotype and ploidy level. European and Japanese plums formed different clusters and a third cluster contained the $P$. insititia and $P$. cerasifera genotypes. The latter species had a higher affinity to $P$. domestica rather than to $P$. salicina. The close relationship between $P$. cerasifera, $P$. domestica and $P$. insititia has been demonstrated based on morphological studies (Woldring, 2000; Nielsen and Olrik, 2001) and confirmed in several genetic analyses (Aradhya et al., 2004; Shaw and Small, 2004; Katayama and Uematsu, 2005). Furthermore, according to Woldring (2000), both morphological similarities between $P$. insititia and $P$. domestica and the incidence of a wide variety of forms with many overlapping structures suggest a close relationship. Overlapping characters between $P$. insititia and related taxa are probably due to the long cultivation history (Gleason, 1958).

In our analysis, as well as in the analysis of Depypere et al. (2009), both species displayed high levels of variation in spite of the relatively low sample sizes, and a tendency towards genetic differentiation. The observed intensive genetic diversity can be explained by a large and frequent recombination within the genus Prunus (Ortiz et al., 1997). Moreover, the high variability and recombination is favoured by the partial self-incompatibility present in plum genotypes and particularly by the capacity of $P$. domestica to intercross and form hybrids with other hexaploid Prunus species as mentioned by Ortiz et al. (1997). Still, the RAPD-ISSR UPGMA clustering and the Bayesian inference (at $\mathrm{K}=2$ ) grouped accessions of $P$. insititia and $P$. domestica to nearby/same clusters. This concurs with other studies (Shaw and Small, 2004; Katayama and Uematsu, 2005), where $P$. insititia and $P$. domestica are shown to have similar cpDNA patterns. Nevertheless, in the AMOVA analysis, as well as, in the Bayesian inference when larger number of populations are simulated (i.e. $K=5$ ), individuals of $P$. insititia and $P$. domestica are clustered separately. Even though $P$. insititia is more primitive than $P$. domestica (Depypere et al., 2009), both taxa originated most probably from a single or very similar ancestral line, differentiated due to human selection and domestication (Woldring, 2000), which could explain their high genetic similarity. Furthermore, Stace (1975) and Zohary (1992) suggest a close relationship amongst the diploid $P$. cerasifera and the hexaploid $P$. domestica. Zohary (1992) also states that $P$. domestica plums, and predominantly $P$. insititia, are morphologically comparable to $P$. cerasifera; this is in accordance with the possibility of a polyploid $P$. cerasifera origin for $P$. domestica (Depypere et al., 2009). In a recent study based on cpDNA sequences, Reales et al. (2010) showed that hexaploid plums "group together with $100 \%$ posterior probability and $87 \%$ bootstrap support in a clade containing $P$. cerasifera, $P$. divaricata and $P$. ursina". Also, Horvath et al. (2011) confirmed this result since most $P$. domestica cpDNA haplotypes grouped together with $P$. cerasifera haplotypes. Therefore Reales et al. (2010) and Horvath et al. (2011) argued that $P$. domestica originated from $P$. cerasifera, at least in its maternal lineage.

In the current study $P$. domestica cultivars were grouped together, in some cases showing weak relationships. Bootstrap support values were rather low, fluctuating from $14 \%$ to $95 \%$. This is also an effect of the complex relationships among the polyploid prunes. The only cultivars showing high affinity were 'Stanley' and 'Bluefree' (95\% bootstrap support) followed by 'Tuleu dulce' and 'Tuleu gras' bistro (95\% bootstrap support). 'Stanley' is acknowledged as the standard plum variety, released by the Cornell-Geneva 
496

station in 1926 (Andersen et al., 2006). 'Bluefree' on the other hand is a more recent cultivar that has been released in order to extend the harvest plum season after 'Stanley'; therefore a common origin cannot be excluded.

Moderate affinity (35\% bootstrap support) was recorded among two of the prune landraces 'Feher besztercei' and 'Mirabelle de Nancy'. Mirabelle plum is believed to have originated in Asia Minor and specifically in the district lying amongst Bosporus and the Black Sea, introduced in Europe through the crusades (the Lorraine region of France). Till present, this region produces almost $70 \%$ of the worlds production of Mirabelle plums. On the other hand, 'Feher besztercei' has a Hungarian origin; it has been reported, that before the 18th century only one outstanding and universal Besztercei plum was cultivated (Surányi, 2006). 'Anna Späth' Pitesti was clustered together with 'President', while 'Anna Späth' Oradea had affinity to the 'Feher besztercei'/'Mirabelle de Nancy' group. 'Anna Späth' is a Hungarian plum of unknown parentage, first raised near Kadoszbeg and discovered by Späth in 1874. Finally, 'President', a very large blue-black dual purpose plum, was developed at the start of the 20th century by the Rivers Nursery, in Hertfordshire, England.

The two Greek plum varieties, 'Goulina' and 'Asvestochoriou', were highly affiliated and somewhat diverged from the foreign cultivars. Especially in the Bayesian analysis, where no admixture was calculated, they were considered as a distinctive population. Finally, two plum accessions, 'Scoldus' SS (broadly used as a rootstock) and 'Kisnanai' (a traditional Hungarian cultivar/landrace also used as a rootstock) had little similarity to other $P$. domestica genotypes and remained as single entities.

Genetic relationship among the diploid Japanese plumes (P. salicina) seems to be less complicated compared to their hexaploid equivalents, since a possible common origin between cultivars is indicating and corroborates with the hypothesis of ploidy level. Prunus salicina, originated in China, was introduced into Japan no earlier than $1500 \mathrm{AD}$. Later on, many cultivars were introduced into California (around 1870) and afterwards to Europe (Liu et al., 2007). The foundations of the Japanese plum cultivation were set by Luther Burbank who introduced several Japanese plum accessions and hybridized them with American native species, resulting in a series of improved cultivars (Ryugo, 1988). This is documented by the limited diversity detected among the plum cultivars in relation to other tree fruit species. The major Japanese plum cultivars decent from a few genotypes produced by hybrization between $P$. salicina, $P$. simonii Carrière and native North American species. Todays breeding programs are utilizing a fraction of improved cultivars, thus narrowing even further the genetic base (Ilgin et al., 2009).

In the present study, $P$. salicina accessions were organized in three subclusters. The first was composed by 'Black Gold' and 'Kelsey', sharing high affinity, and clearly separated by the other two sublusters. 'Kelsey' is one of the oldest cultivars introduced from Japan, more than 100 years ago, while 'Black Gold' was bred and patented in 1980 by Superior Farms (Okie and Ramming, 1999). The close genetic affinity among them and the Bayesian analysis (at $\mathrm{k}=2$ and $\mathrm{k}=5$ ) indicates that the genetic composition of the latter has a proportion of the 'Kelsey' genotype. The second subgroup is composed by cultivars 'Angeleno', 'Black Beauty' and 'Friar' (the predominant plum in the industry, since it is very productive with large fruit and its black skin colour does not show bruises). 'Angeleno' and 'Black Beauty' have been both produced by a hybridization of 'Gariota' $x$ 'Eldorado' and share common lineage, while 'Friar' has a partial 'Santa Rosa' genotype (Okie and Ramming, 1999). The last subgroup contains 'Santa Rosa', 'Black Diamond' and 'Calita.' 'Santa Rosa' is a complex hybrid produced by Luther Burbank, 'Black Diamond' is also produced by a 'Gariota' $x$ 'Eldorado' crossing and 'Calita' was released as a seedling (Okie and Ramming, 1999). Therefore, nowadays $P$. salicina cultivars have a narrow genetic base and almost 10 cultivars producing about $75 \%$ of the total world production in recent years. The rest $25 \%$ is produced by other secondary cultivars, which are essentially derived from the same germplasm, all trace back to just five parents and released by Luther Burbank: 'Santa Rosa, 'Eldorado, 'Gaviota,' 'Formosa' and 'Burbank' (Okie and Ramming, 1999). Hence, it is clear from the parentages that many introductions are mutations or chance seedlings, rather than the result of planned hybridizations.

In conclusion, ISSR and RAPD markers permitted the distinction between plum species and established the identity of the Greek National plums collection. The correlation among the molecular techniques suggests their utility for identification and characterization of germplasm and could provide a profound understanding of plum germplasm diversity.

\section{Conclusions}

In conclusion, the current work revealed the equivalent effectiveness of RAPD and ISSR markers for the investigation of the Greek plum germplasm diversity and its relationships to introduced accessions. High inter- and intra- genetic variability was recorded among Prunus spp. and related genera; clustering reflected association among most of the accessions according to species genotype/ ploidy. Greek cultivars 'Goulina' and 'Asvestochoriou' revealed a distinctive genetic composition that differentiated them from the other $P$. domestica accessions. Possibly the estimation of diversity among these genotypes can be significant for implementation in future breeding programs.

\section{References}

Andersen R, Freer J, Weber C (2006). A Century of Plum breeding at Geneva. New York Fruit Quarterly 14:1.

Aradhya MK, Weeks C, Simon CJ (2004). Molecular charac- 
terization of variability and relationships among seven cultivated and selected wild species of Prunus L. using amplified fragment length polymorphism. Sci Hortic 103:131-144.

Aran M, Fatahi R, Zamani Z (2012). Molecular and morphological discrimination of selected plum seedlings for rootstock breeding. J Fruit Ornam Plant Res 20:5-19.

Banegal NB (1954). History and development of the cultivated fruits. Ass Agric Rev 24:21-28.

Belaj A, Satovic Z, Cipriani G, Baldoni L, Testolin R, Rallo L, Trujillo I (2003). Comparative study of the discriminating capacity of RAPD, AFLP and SSR markers and of their effectiveness in establishing genetic relationships in olive. Theor Appl Genet 107:736-744.

Casas EM, Igartua E, Balaguer G, Moreno MA (1999). Genetic diversity of Prunus rootstoks analyzed by RAPD markers. Euphytica 110:139-149.

Crane MB, Lawrence WJC (1952). The Genetics of Garden Plants. Macmillan, London.

Cullinan FP (1937). Improvement of stone fruits. In: Cullinan FP, Weinberger JH (Ed.) USDA yearbook of agriculture. Washington, DC. p. 605-702.

Depypere L, Chaerle P, Breyne P, Vander Mijnsbrugge K, Goetghebeur P (2009). A combined morphometric and AFLP based diversity study challenges the taxonomy of the European members of the complex Prunus L. section Prunus. Plant Syst Evol 279:219-231.

Despotaki E, Linos A, Hagidimitriou M (2011). Studying the genetic variation among clones of 'Kalamon' and 'Koroneiki' using molecular techniques. Acta Hortic 924:335-340.

Doyle JJ, Doyle JL (1987). A rapid DNA isolation procedure for small quantities of fresh leaf tissue. Phytochem Bull 19:11 15 .

Eryomine GV (1991). New data on origin of Prunus domestica L. Acta Hortic 283:27-29.

Gleason HA (1958). Illustrated Flora of the Northeastern United States and Adjacent Canada. In: Lancaster, PA (Ed.) Lancaster Press, Inc.

Hend BT, Ghada B, Sana BM, Mohamed M, Mokhtar T, Amel SH (2009). Genetic relatedness among Tunisian plum cultivars by random amplified polymorphic DNA analysis and evaluation of phenotypic characters. Sci Hortic 121:440446.

Horvath A, Balsemin E, Barbot JC, Christmann H, Manzano G, Reynet P, Laigret F, Mariette S (2011). Phenotypic variability and genetic structure in plum (Prunus domestica L.), cherry plum (P. cerasifera Ehrh.) and sloe (P. spinosa L.). Sci Hortic 129:283-293.

Ilgin, M, Kafkas S, Ercisli S (2009). Molecular characterization of plum cultivars by AFLP markers. Biotechnol Biotech Eq 23:1189-1193.

Katayama H, Uematsu C (2005). Structural analysis of chloroplast DNA in Prunus (Rosaceae): evolution, genetic diversity and unequal mutations. Theor Appl Genet 111:1430439.
Kumar M, Mishra GP, Singh R, Kumar J, Naik PK, Sing (2009). Correspondence of ISSR and RAPD markers for comparative analysis of genetic diversity among different apricot genotypes from cold arid deserts of trans Himalayas. Physiol Mol Biol P 15:225-236.

Liu W, Li S, Zhang A, Liu D (2007). Genetic diversity revealed by RAPD markers in plum collection of China. Acta Hortic 734:287-294.

Mabberley DJ (2008). Mabberleys plant-book. A portable dictionary of plants, their classification and uses. 3rd edn Cambridge University Press, Cambridge.

Nielsen J, Olrik DC (2001). A morphometric analysis of Prunus spinosa, $P$. domestica ssp. insititia, and their putative hybrids in Denmark. Nordic J Bot 21(4):349-363.

Okie WR, Ramming DW (1999). Plum breeding worldwide. Hort Technol 9:162-176.

Ortiz A, Renaud R, Calzada I, Ritter E (1997). Analysis of plum cultivars with RAPD markers. J Hortic Sci 72:1-9.

Pavlicek A, Hrda S, Flegr J (1999). FreeTree - freeware program for construction of phylogenetic trees on the basis of distance data and bootstrapping/jack-knife analysis of the tree robustness. Application in the RAPD analysis of the genus Frenkelia. Folia Biol (Praha.) 45:97-99.

Peakall R, Smouse PE (2006). GENALEX 6: genetic analysis in Excel. Population genetic software for teaching and research. Mol Ecol Notes 6:288-295.

Pritchard JK, Stephens M, Donnelly P (2000). Inference of population structure using multilocus genotype data. Genetics 155:945-959.

Ramming DW, Cociu V (1990). Plum (Prunus). Acta Hortic 290:235-287.

Reales A, Sargent DJ, Tobut KR, Rivera D (2010). Phylogenetics of Eurasian plums, Prunus L. section Prunus (Rosaceae), according to coding and non-coding chloroplast DNA sequences. Tree Genet Genomes 6:37-45.

Rohlf FJ (2000). NTSYS-pc: numerical taxonomy and multivariate analysis system. Exeter Publ, Setauket, NY.

Ryugo K (1988). Fruit culture: its science and art. Wiley, New York.

Shaw J, Small RL (2004). Addressing the hardest puzzle in American pomology: Phylogeny of Prunus sect. Prunocerasus (Rosaceae) based on seven noncoding chloroplast DNA regions. Am J Bot 91:985-996.

Shimada T, Hayama H, Haji T, Yamaguchi M, Yoshida M (1999). Genetic diversity of plums characterized by random amplified polymorphic DNA (RAPD) analysis. Euphytica, 109:143-147.

Stace CA (1975). Hybridization and the Flora of the British Isles. Academic Press, London.

Surányi D (2006). Comparative study of different fertile groups in plums. Int J Hortic Sci 12:71-76.

Westwood MN (1993). Temperate-zone pomology: physiology and culture. Timber Press, Portland, OR. 
498

Woldring H (2000). On the origin of plums: a study of sloe, damson, cherry plum, domestic plums and their intermediates. Palaeohistoria 39(40):535-562.

Zohary D (1992). Is the European plum, Prunus domestica L., a P. cerasifera Ehrh. x P. spinosa L. allo-polyploid? Euphytica
60:75-77.

Zohary D, Hopf M (1994). Domestication of plants in the Old World. $2^{\text {nd }}$ edn Clarendon Press, Oxford, p 279. 